\title{
Potencial Alelopático de Extratos Aquosos de Genótipos de Canola sobre Bidens pilosa
}

\author{
Allelopathic Potential of Aqueous Extracts of Canola Genotypes on Bidens Pilosa
}

RIZZARDI, A. ${ }^{2}$, RIZZARDI, M.A. ${ }^{3}$, LAMB, T.D. ${ }^{4}$ e JOHANN, L.B. ${ }^{4}$

\begin{abstract}
RESUMO - O objetivo deste trabalho foi avaliar o efeito de extratos aquosos de plantas de genótipos de canola na germinação e comprimento da radícula de picão-preto (Bidens pilosa). Os tratamentos estudados foram constituídos dos genótipos de canola Hyola 420, Hyola 401, Hyola 43, Hyola 60, Hyola 61, Y 3000, H 1432, Dln 03-02, Dln 03-04, Sdh 03-01, Sdh 0307, Sw-2797 e Sw-Eclipse, nas concentrações de extrato aquoso a 100, 75, 50, 25 e 0\%. O delineamento experimental foi inteiramente casualizado, em esquema fatorial com dois fatores 12 x 4 (genótipos e concentração do extrato), com quatro repetições. O experimento foi conduzido em caixas gerbox com papel de germinação embebido nos extratos das plantas de canola, sobre os quais foram dispostos aquênios de picão-preto. Sete dias após a semeadura, avaliou-se o número de aquênios germinados e o comprimento das radiculas. Os resultados revelaram que os extratos de canola influenciam negativamente a germinação de aquênios e o comprimento da radicula de Bidens pilosa. Para alguns genótipos, as baixas concentrações de extratos estimularam tanto o crescimento da radicula quanto a porcentagem de germinação dos aquênios; em altas concentrações, os genótipos não diferiram na germinação dos aquênios e no comprimento da radícula.
\end{abstract}

Palavras-chave: $\quad$ alelopatia, picão-preto, Brassica napus, oleifera

\begin{abstract}
The objective of this experiment was to evaluate the effect of aqueous extract of plants of canola genotypes on the germination and radicle length of hairy beggartick (Bidens pilosa). The treatments consisted of genotypes of canola Hyola 420, Hyola 401, Hyola 43, Hyola 60, Hyola 61, Y 3000, H 1432, Dln 03-02, Dln 03-04, Sdh 03-01, Sdh 03-07, sw-2797, and SwEclipse. The concentrations of aqueous extract of 100, 75, 50, 25 and $0 \%$ were tested. A completely randomized experimental design was used in a factorial $12 \times 4$ (genotypes and extract concentrations) with four replications. The experiment was carried out in plastic boxes containing ot the bottom blotter paper moistened with the aqueous extract, where the hairy beggartick achenes were seeded. Seven days later, the number of germinated achenes was evaluated and the length of radicles measured. The results showed that the canola extracts negatively influenced achene germination and radicle length. The effects increased with increased extract concentrations. At low concentration, some genotype extracts presented a stimulating effect. The results showed that the variability among canola genotypes was only evident at low extract concentrations.
\end{abstract}

Keywords: alellophaty, hairy beggartick, Brassica napus, oleifera.

1 Recebido para publicação em 3.12.2007 e na forma revisada em 25.5.2008.

2 Bióloga, aluna do Programa de Pós-graduação em Agronomia - UPF; ${ }^{3}$ Engo-Agro ${ }^{-}$, Professor da Faculdade de Agronomia e Medicina Veterinária - UPF, Bolsista do CNPq, Caixa Postal 611, 99001-970, Passo Fundo, <RS, rizzardi@upf.br>; ${ }^{4}$ Acadêmicos do Curso de Agronomia, UPF, Bolsistas de Iniciação Científica do CNPq e Fapergs.

Planta Daninha, Viçosa-MG, v. 26, n. 4, p. 717-724, 2008 


\section{INTRODUÇÃO}

A alelopatia é uma interação química que ocorre entre os vegetais e desempenha papel importante em diversos ecossistemas (Mairesse, 2005). Esse tipo de interação foi definido por Rice (1984) como qualquer efeito direto ou indireto, danoso ou benéfico, que uma planta exerce sobre outra pela produção de substâncias químicas liberadas no ambiente.

A atividade dos aleloquímicos tem sido usada como alternativa ao uso de herbicidas, nematicidas e inseticidas (Norsworthy \& Meehan, 2005). A maioria dessas substâncias provém do metabolismo secundário, que na evolução das plantas representa vantagem contra a ação de microrganismos, vírus, insetos e outros patógenos ou predadores, seja inibindo a ação destes ou estimulando o crescimento e desenvolvimento das plantas (Wu et al., 1999).

Os resultados de laboratório são o primeiro passo para a identificação do comportamento de plantas associado com aleloquímicos (Elakovitch, 1999; Mairesse, 2005). Os bioensaios consistem em monitorar a germinação de sementes e/ou o crescimento de plântulas de espécies vegetais, peculiarmente mais sensiveis, na presença de resíduos da planta em estudo ou através da elaboração de extratos (Rice, 1984). A inibição ou o estímulo da germinação ou o crescimento de plântulas são evidências da atividade alelopática (Mairesse, 2005). Nesse sentido, a alelopatia possui potencial no manejo integrado de plantas daninhas, pela capacidade que as plantas têm, inclusive as cultivadas, de produzirem aleloquímicos que inibem o crescimento de plantas daninhas (Wu et al., 1999). A produção de herbicidas a partir dos aleloquímicos e o cultivo de plantas consorciadas ou em sucessão adequadamente escolhidas parecem ser viáveis (Jacobi \& Fleck, 2000). Além disso, é uma alternativa para o manejo integrado de plantas daninhas (Buhler, 2002).

O manejo de plantas daninhas com o uso da alelopatia dependerá da escolha adequada da cultura a ser utilizada e do somatório dos efeitos alelopáticos individuais dessas culturas (Buhler, 2002). A tentativa de obter plantas cultivadas com maior potencial alelopático para que possam competir com plantas daninhas baseia-se não apenas no resgate dessa característica presente em tipos silvestres, mas também na seleção de genótipos que possam mostrar maior ou menor ação alelopática (Jacobi \& Fleck, 2000).

Estudos realizados com plantas pertencentes à família Brassicaceae, à qual pertence a canola, indicaram que espécies dessa família produzem altas concentrações de um metabólito secundário denominado glucosinolato, cujo produto de sua hidrólise dá origem a diferentes aleloquímicos (Eberlein et al., 1998; Oerlemans et al., 2006). Os glucosinolatos também são referidos como substância de defesa natural de plantas contra a herbivoria, visto que são tóxicos para a maioria dos animais (Jönsson, 2005).

A cultura da canola possui potencial na produção de óleos vegetais e biocombustivel e é estudada quanto ao seu potencial alelopático (Rizzardi et al., 2008). Castro et al. (1983) constataram que extratos de Brassica napus inibiram a germinação e o crescimento da radícula de alface e tomateiro e relataram também que a canola afeta o desenvolvimento de outras espécies cultivadas. A incorporação no solo de plantas do gênero Brassica como adubação verde reduziu a emergência e biomassa de plantas daninhas e soja, além de diminuir o rendimento de grãos da cultura (Krishnan et al., 1998). Rizzardi et al. (2008) observaram efeito inibitório de extratos de folhas, raízes e caule de canola na velocidade de emergência e na porcentagem de germinação de picão-preto e soja.

Levando em consideração a possivel existência de diferenças entre genótipos de canola (Brassica napus L. var. oleifera) com relação ao potencial alelopático, objetivou-se neste trabalho avaliar o efeito de extratos aquosos de genótipos de canola na germinação e no comprimento da radícula de picão-preto.

\section{MATERIAL E MÉTODOS}

O experimento foi realizado no Centro de Extensão e Pesquisa Agropecuária (Cepagro) e no Centro de Pesquisa em Alimentação (Cepa), da Universidade de Passo Fundo/RS, durante o ano de 2006.

O delineamento experimental foi inteiramente casualizado, em esquema fatorial com 
dois fatores (concentração do extrato e genótipos) e quatro repetições. $O$ fator concentração teve cinco niveis $(100,75,50,25$ e $0 \%)$, e o fator genótipo, 13 niveis (Hyola 420, Hyola 401, Hyola 43, Hyola 60, Hyola 61, Y 3000, H 1432, Dln 03-02, Dln 03-04, Sdh 03-01, Sdh 03-07, Sw-2797 e Sw-Eclipse). O experimento foi conduzido em caixas gerbox, representando as unidades experimentais.

Os genótipos de canola foram cultivados individualmente em casa de vegetação, em canteiros medindo $2 \times 1 \mathrm{~m}$, utilizando-se solo classificado como Latossolo Vermelho-Escuro típico. A adubação constou de $12,5 \mathrm{~kg}$ de $\mathrm{N} \mathrm{ha}^{-1}$, $50 \mathrm{~kg}$ de $\mathrm{P}_{2} \mathrm{O}_{5}$ ha $^{-1}$ e $50 \mathrm{~kg}$ de $\mathrm{K}_{2} \mathrm{O} \mathrm{ha}^{-1}$. A irrigação foi realizada com sistema de aspersão. Ao atingir o estádio de florescimento, a parte aérea e as raízes das plantas foram colhidas e levadas ao laboratório.

Em laboratório, a canola passou por processo de lavagem e assepsia, sendo posteriormente cortada em pedaços de aproximadamente $0,5 \mathrm{~cm}$ e congelada à temperatura de aproximadamente $-30{ }^{\circ} \mathrm{C}$ por 15 horas, processos esses necessários para a liofilização. Depois de congelada, era levada ao liofilizador, onde permanecia aproximadamente 12 horas, até a desnaturação do vegetal. O material proveniente da liofilização era moído e depois acondicionado em recipientes de vidro, sendo guardado em congelador até o preparo do extrato.

Da canola liofilizada e moída foi produzido o extrato, que consistiu em água (Milli- $\mathrm{Q}^{\circledR} \mathrm{e}$ esterilizada) e canola na proporção de $8 \mathrm{~g}$ de material seco/100 mL de solvente. Essa solução foi mantida à temperatura de $25^{\circ} \mathrm{C}$, em agitador mecânico, durante 24 horas. Após esse período, a solução foi centrifugada na rotação de 3.000 rpm durante cinco minutos, coletando-se em seguida o líquido sobrenadante. A solução resultante obtida (extrato $100 \%$ ) foi utilizada no preparo das diluições. As concentrações utilizadas foram: $100,75,50$ e $25 \%$, empregando-se água (Milli-Q ${ }^{\circledR}$ e esterilizada) como testemunha $(0 \%)$.

Os aquênios de Bidens pilosa (picão-preto) foram coletados, em área de cultivo de soja, no ano de 2005, sendo selecionados e acondicionados em sacos de papel. Para realização do experimento, passaram por processo de assepsia com hipoclorito de sódio (50\%) e água destilada (50\%), ficando imersos nessa solução por cinco minutos; por último, procedeu-se ao enxágüe com água destilada. Depois disso, papéis de germinação germitest foram embebidos com $8 \mathrm{~mL}$ do extrato e colocados em caixa do tipo gerbox, para posteriormente receberem 30 aquênios de picão-preto.

A semeadura foi realizada em câmara de fluxo de ar com o auxílio de pinça. As caixas semeadas foram identificadas e acondicionadas em câmara de germinação, permanecendo no local, em temperatura de $22,5^{\circ} \mathrm{C}$, com fotoperíodo de 12 horas de luz e 12 horas de escuro durante sete dias, quando se efetuou a contagem do número de plântulas germinadas. Foram consideradas plântulas normais as que desenvolveram estruturas essenciais da parte aérea e radicular, e plântulas anormais, as que não germinaram ou tiveram estruturas defeituosas. Também aos sete dias, avaliouse o comprimento das radículas emitidas, utilizando-se paquímetro digital.

Os dados coletados no experimento foram submetidos à análise de variância através do teste $\mathrm{F}$, e as médias foram comparadas pelo teste de Tukey a $5 \%$ de probabilidade. Quando houve significância das concentrações e de sua interação com os genótipos, procedeu-se à análise de regressão, com uso de modelos polinomiais. Realizou-se ainda a análise dos coeficientes $\beta$ das equações de regressão linear através da comparação pelo teste $t$, a fim de avaliar a existência de diferenças entre os genótipos quanto ao efeito inibitório para as duas variáveis analisadas.

\section{RESULTADOS E DISCUSSÃO}

Os resultados da análise de variância para a variável germinação de aquênios de picãopreto indicaram a existência de interação de concentração do extrato e genótipo (Figura 1). A porcentagem de germinação dos aquênios de picão-preto diminuiu linearmente, para todos os genótipos, à medida que se aumentou a concentração do extrato (Figura 1). Segundo Kato-naguchi et al. (1994), a atividade biológica dos extratos vegetais depende tanto da concentração do aleloquímico quanto do limite da resposta da espécie afetada; no presente trabalho, esses pontos foram marcantes quando se observa a relação negativa entre a 


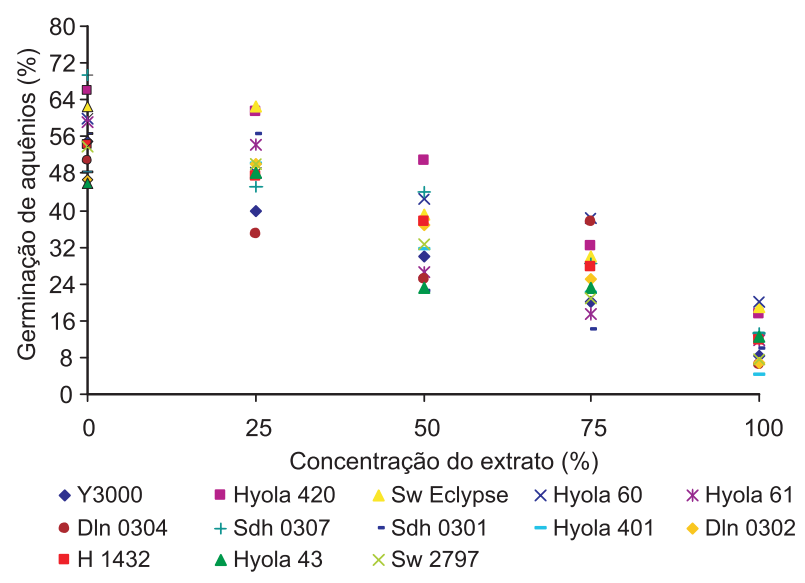

Figura 1 - Efeito da concentração do extrato de genótipos de canola (Brassica napus) sobre a porcentagem de germinação de aquênios de picão-preto. UPF, Passo Fundo, RS, 2006.

concentração e a inibição da germinação dos aquênios.

Na média dos 13 genótipos avaliados, o aumento da concentração do extrato de 0 para $100 \%$ reduziu a germinação em $80 \%$, o que mostra a existência de efeito supressor do extrato de canola sobre a germinação de aquênios de picão-preto (Figura 1). Resultados semelhantes foram observados por Rizzardi et al. (2008), em que o aumento da concentração do extrato reduziu, em média, em $83 \%$ a germinação de picão-preto e em $31 \%$ o índice de velocidade de emergência da soja.

Ao analisar individualmente os genótipos avaliados, o aumento na concentração do extrato para $100 \%$ diminuiu a germinação de picão-preto na seguinte ordem: Hyola 401 $(91,5 \%)>\mathrm{D} \ln 0304(87 \%)>\mathrm{D} \ln 0302(86 \%)>\mathrm{Y}$ $3000(85 \%)>$ Sw 2797 (85\%) > Sdh 0301 $(82,5 \%)>$ Sdh $0307(81 \%)>$ Hyola $61(80 \%)>$ H $1432(78,6 \%)>$ Hyola $420(73,5 \%)>$ Hyola 43 $(73 \%)>$ Sw Eclypse $(70 \%)>$ Hyola 60 (67\%). Essas variações no percentual de germinação podem indicar diferenças quanto à intensidade do efeito dos extratos entre os genótipos testados. Os resultados do teste $t$ mostraram a inexistência de diferenças no coeficiente $\beta$ das equações lineares dos 13 genótipos avaliados (Tabela 1), indicando similaridade na habilidade de suprimir a germinação de picão-preto à medida que se aumentou a concentração do extrato de 0 para $100 \%$.
Tabela 1 - Equações da regressão e significância do teste t entre os genótipos de canola, na avaliação da germinação de aquênios de picão-preto. UPF, Passo Fundo, RS, 2006

\begin{tabular}{|l|l|c|c|c|}
\hline \multicolumn{1}{|c|}{ Genótipo } & $\begin{array}{c}\text { Equação de } \\
\text { regressão }\end{array}$ & $\mathrm{r}^{2}$ & $\mathrm{P}$ & ${\text { Teste } \mathrm{t}^{\mathrm{1}}}^{\text {- }}$ \\
\hline Y 3000 & $\mathrm{y}=97,2-82,8 \mathrm{x}$ & 0,99 & 0,0001 & $\mathrm{~ns}$ \\
\hline Hyola 420 & $\mathrm{y}=107,0-76,4 \mathrm{x}$ & 0,95 & 0,0001 & $\mathrm{~ns}$ \\
\hline Sw - Eclypse & $\mathrm{y}=106,4-76,8 \mathrm{x}$ & 0,93 & 0,0001 & $\mathrm{~ns}$ \\
\hline Hyola 60 & $\mathrm{y}=99,6-60,4 \mathrm{x}$ & 0,94 & 0,0001 & $\mathrm{~ns}$ \\
\hline Hyola 61 & $\mathrm{y}=101,6-88,8 \mathrm{x}$ & 0,92 & 0,0001 & $\mathrm{~ns}$ \\
\hline Dln 0304 & $\mathrm{y}=99,6-77,6 \mathrm{x}$ & 0,90 & 0,0001 & $\mathrm{~ns}$ \\
\hline Sdh 0307 & $\mathrm{y}=95,0-74,8 \mathrm{x}$ & 0,94 & 0,0001 & $\mathrm{~ns}$ \\
\hline Sdh 0301 & $\mathrm{y}=105,4-95,6 \mathrm{x}$ & 0,89 & 0,0001 & $\mathrm{~ns}$ \\
\hline Hyola 401 & $\mathrm{y}=112,8-96,4 \mathrm{x}$ & 0,91 & 0,0001 & $\mathrm{~ns}$ \\
\hline Dln 0302 & $\mathrm{y}=116,2-90,4 \mathrm{x}$ & 0,87 & 0,0001 & $\mathrm{~ns}$ \\
\hline H 1432 & $\mathrm{y}=104,8-78 \mathrm{x}$ & 0,97 & 0,0001 & $\mathrm{~ns}$ \\
\hline Hyola 43 & $\mathrm{y}=106,4-79,6 \mathrm{x}$ & 0,86 & 0,0001 & $\mathrm{~ns}$ \\
\hline Sw - 2797 & $\mathrm{y}=106,8-91,2 \mathrm{x}$ & 0,97 & 0,0001 & $\mathrm{~ns}$ \\
\hline
\end{tabular}

${ }^{1 /}$ Teste $t$, aplicado aos coeficientes $\beta$ das equações de regressão na comparação dos genótipos de canola.

$\mathrm{ns}=$ não-significativo a $5 \%$ de probabilidade de erro

$\mathrm{Na}$ avaliação da porcentagem de germinação em cada concentração, a proximidade dos pontos indica pouca variação entre os genótipos (Figura 1). Quanto mais distantes estiverem os pontos, maiores são as variações entre os genótipos quanto à redução da porcentagem de germinação causada pelos extratos. Observa-se, na concentração de $25 \%$, que os pontos estão mais afastados que na concentração de $100 \%$, indicando que nas menores concentrações existem maiores diferenças entre os genótipos quanto à inibição da germinação (Figura 1).

De maneira geral, houve pouca variação na porcentagem de germinação de aquênios de picão-preto na testemunha sem extrato (Figura 1). Nesse tratamento, a germinação média foi de $56 \%$, com intervalo que variou de 45,8 a $69,2 \%$, respectivamente para os genótipos Hyola 43 e Sdh 0307.

Na concentração de $25 \%$, o genótipo Dln 0304 foi o que mais reduziu a germinação de picão-preto, embora diferindo estatisticamente só dos genótipos Hyola 420 e Sw-Eclypse. $\mathrm{Na}$ concentração de $50 \%$, os genótipos Sdh 0301, Hyola 43, Dln 0304 e Hyola 61 foram os que mais reduziram a germinação de picãopreto. Já na concentração de $75 \%$, somente o genótipo Sdh 0301 apresentou redução mais intensa na germinação de picão-preto.

Na concentração de 100\% não foram observadas diferenças entre os 13 genótipos, ficando 
os pontos, que representam os genótipos, muito próximos (Figura 1). A maior redução na germinação dos aquênios de picão-preto ocorreu nessa concentração e foi de $79,6 \%$ na média de todos os genótipos.

Esses resultados mostram que, em baixas concentrações do extrato, os genótipos se comportam de maneira diferente, alguns até mesmo estimulando a germinação; já em altas concentrações, inibem com a mesma intensidade a germinação. Esses efeitos estão provavelmente associados à presença de metabólitos secundários existentes no extrato de canola. A familia Brassicaceae caracteriza-se por produzir glucosinolatos (Oerlemans et al., 2006), que, quando decompostos, transformam-se em isotiocianatos e tiocianatos (Eberlein et al., 1998). Essas substâncias podem, em baixas concentrações, atrasar a germinação e, em altas concentrações, penetrar nas sementes, tornando-as inviáveis (Petersen et al., 2001).

Os resultados da análise do comprimento da radícula mostraram-se muito semelhantes aos da variável porcentagem de germinação de aquênios. A análise de variância indicou a existência de interação de concentração do extrato e genótipos (Figura 2). O comprimento da radícula diminuiu linearmente para todos os genótipos à medida que se aumentou a concentração do extrato (Figuras 2 e 3). O aumento da concentração de 0 para $100 \%$ reduziu, em média, em $78,6 \%$ o comprimento da radícula.

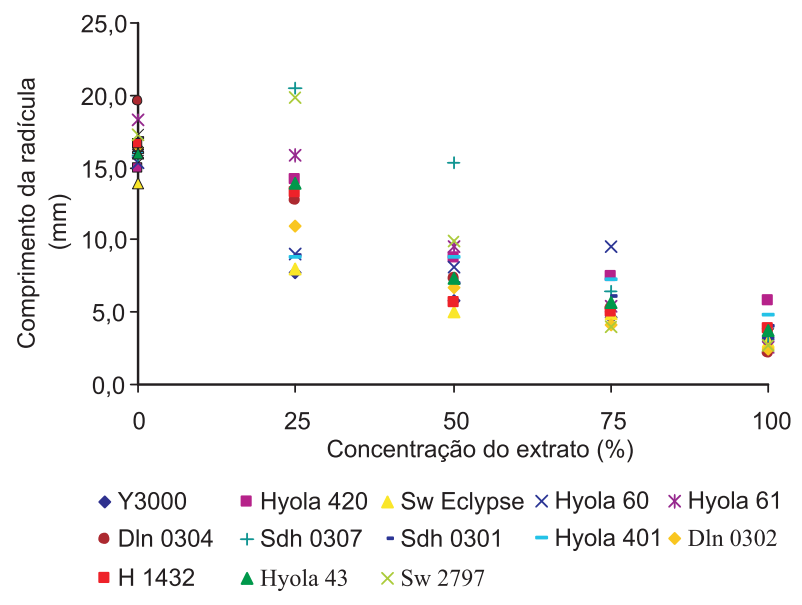

Figura 2 - Efeito da concentração do extrato de 13 genótipos de canola (Brassica napus) sobre o comprimento da radícula $(\mathrm{mm})$ de picão-preto (Bidens pilosa). UPF, Passo Fundo-RS, 2006.
Na análise individual dos genótipos avaliados, o aumento da concentração do extrato de 0 para $100 \%$ diminuiu o comprimento da radicula de picão-preto na seguinte ordem decrescente: Dln 0304 (90\%) > Dln 0302 (87,5\%) > Hyola 61 (83,4\%) > Sw - 2797 (82\%) > Y 3000 $(81 \%)>$ Sdh 0307 (81,3\%) > Sw - Eclypse (79\%) $>$ Sdh 0301 (76\%) > H $1432(76,5 \%)>$ Hyola 43 $(75 \%)>$ Hyola $60(73 \%)>$ Hyola 401 (69\%) > Hyola 420 (60\%). Essas variações na redução do comprimento da radícula indicam haver diferenças quanto à intensidade do efeito dos extratos entre os genótipos testados. Os resultados do teste $\mathrm{t}$ mostraram a inexistência de diferença no coeficiente $\beta$ das equações lineares dos 13 genótipos avaliados (Tabela 2). Esses resultados indicam que os genótipos foram similares na habilidade de reduzir a expansão das radículas.

Ao comparar as médias dos 13 genótipos na concentração de $25 \%$, observam-se variações entre eles, que podem ser visualizadas pelo afastamento dos pontos (Figura 2). Os genótipos Y 3000 e Sw-Eclypse foram os que mais reduziram o comprimento da radícula. Para essa variável, os genótipos Sw - 2797 e Sdh 0307 estimularam o crescimento. Esses resultados de estímulo de germinação ou comprimento da radicula provavelmente devem-se à presença de alguns aleloquímicos com ação

Tabela 2 - Equações da regressão e significância do teste t entre os genótipos de canola, na avaliação do comprimento da radícula de picão-preto. UPF, Passo Fundo-RS, 2006

\begin{tabular}{|l|c|c|c|c|}
\hline \multicolumn{1}{|c|}{ Genótipo } & $\begin{array}{c}\text { Equação de } \\
\text { regressão }\end{array}$ & $\mathrm{r}^{2}$ & $\mathrm{P}$ & Teste $^{\mathrm{I}^{\mathrm{I}}}$ \\
\hline Y 3000 & $\mathrm{y}=13,35-0,11 \mathrm{x}$ & 0,80 & 0,0001 & $\mathrm{~ns}$ \\
\hline Hyola 420 & $\mathrm{y}=15,28-10,1 \mathrm{x}$ & 0,92 & 0,0001 & $\mathrm{~ns}$ \\
\hline Sw - Eclypse & $\mathrm{y}=12,00-0,10 \mathrm{x}$ & 0,85 & 0,0001 & $\mathrm{~ns}$ \\
\hline Hyola 60 & $\mathrm{y}=13,72-9,18 \mathrm{x}$ & 0,73 & 0,0001 & $\mathrm{~ns}$ \\
\hline Hyola 61 & $\mathrm{y}=18,71-0,16 \mathrm{x}$ & 0,98 & 0,0001 & $\mathrm{~ns}$ \\
\hline Dln 0304 & $\mathrm{y}=17,88-0,16 \mathrm{x}$ & 0,94 & 0,0001 & $\mathrm{~ns}$ \\
\hline Sdh 0307 & $\mathrm{y}=20,12-0,15 \mathrm{x}$ & 0,75 & 0,0001 & $\mathrm{~ns}$ \\
\hline Sdh 0301 & $\mathrm{y}=14,35-0,11 \mathrm{x}$ & 0,82 & 0,0001 & $\mathrm{~ns}$ \\
\hline Hyola 401 & $\mathrm{y}=13,92-0,09 \mathrm{x}$ & 0,82 & 0,0001 & $\mathrm{~ns}$ \\
\hline Dln 0302 & $\mathrm{y}=15,08-0,13 \mathrm{x}$ & 0,95 & 0,0001 & $\mathrm{~ns}$ \\
\hline H 1432 & $\mathrm{y}=15,60-0,13 \mathrm{x}$ & 0,87 & 0,0001 & $\mathrm{~ns}$ \\
\hline Hyola 43 & $\mathrm{y}=15,84-0,13 \mathrm{x}$ & 0,93 & 0,0001 & $\mathrm{~ns}$ \\
\hline Sw - 2797 & $\mathrm{y}=19,71-0,17 \mathrm{x}$ & 0,85 & 0,0001 & $\mathrm{~ns}$ \\
\hline
\end{tabular}

$\underline{1}$ / Teste $t$, aplicado aos coeficientes $\beta$ das equações de regressão na comparação dos genótipos de canola.

$\mathrm{ns}=$ não-significativo a $5 \%$ de probabilidade de erro. 

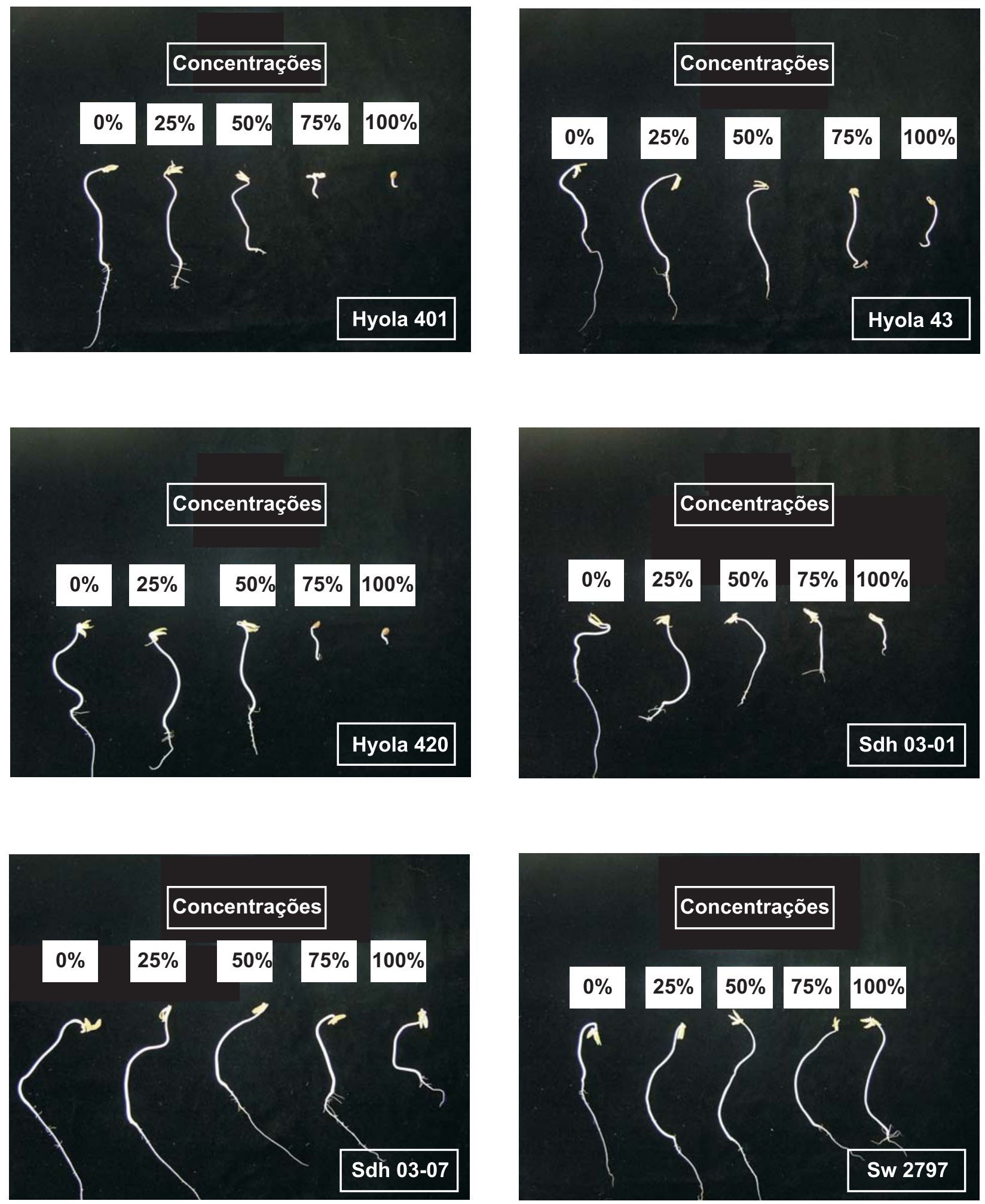

Figura 3 - Efeito da concentração do extrato de genótipos de canola (Brassica napus) no comprimento da radícula de picão-preto (Bidens pilosa). 
estimulatória - esse fato pode ser caracterizado como efeito alelopático (Carvalho et al., 2002).

Na concentração de $25 \%$, na média dos genótipos, o comprimento da radícula diminuiu $23,1 \%$ quando comparado com o da testemunha. Entre os genótipos, a ordem de redução foi: Y $3000(50 \%)>$ Sdh $0301(47,1 \%)>$ Hyola $401(44 \%)>$ Sw - Eclypse (43\%) > Hyola 60 (40\%) $>\mathrm{D} \ln 0304(35 \%)>\mathrm{D} \ln 0302(31 \%)>\mathrm{H} 1432$ $(23,6 \%)>$ Hyola $43(12,5 \%)>$ Hyola $61(12 \%)>$ Hyola $420(6,7 \%)>$ Sw $-2797(+17 \%)>$ Sdh 0307 $(+25 \%)$.

Nas concentrações de 50 e $75 \%$, os genótipos se comportaram de maneira similar. $\mathrm{Na}$ concentração de 50\%, o genótipo Sdh 0307 foi o que menos influenciou o comprimento da radícula; já para os demais genótipos os efeitos foram similares. Na concentração de $75 \%$, o genótipo com menor influência no comprimento da radícula foi o Hyola 60.

Na concentração de 100\% não foram constatadas diferenças entre os genótipos. Nessa concentração, os pontos se aproximaram e a redução média no comprimento da radícula foi de $78,7 \%$, em relação à testemunha (Figura 2). De acordo com Souza Filho et al. (1997), a interferência no desenvolvimento da radícula é um dos melhores indicadores para o estudo de extratos com potencial alelopático.

Apesar de não serem constatadas diferenças entre os genótipos na intensidade de redução (Tabelas 1 e 2), observou-se que as concentrações dos extratos de canola exercem efeito inibitório diferenciado entre os genótipos, tanto na germinação dos aquênios (Figura 1) quanto no comprimento da radícula do picãopreto (Figura 2). Essas diferenças foram significativas principalmente em baixas concentrações do extrato. Uma das explicações para o observado pode-se dever ao efeito alelopático que as plantas da família das brássicas exercem. Entre os metabólitos secundários existentes nessas plantas estão os glucosinolatos (Norsworthy, 2003). A hidrólise dos glucosinolatos gera produtos voláteis, entre eles os isotiocianatos, que possuem acentuado efeito alelopático sobre uma série de espécies vegetais (Brown et al., 1991). Segundo Norsworthy \& Meehan (2005), uma das principais características desse composto é sua atividade herbicida.
Pode-se concluir que os extratos de canola nas concentrações de 25,50 e $75 \%$ influenciam negativamente a germinação de aquênios e o comprimento da radícula de picãopreto, sendo um indicativo para estudos mais detalhados sobre a capacidade alelopática da própria espécie em estudo, assim como de outras espécies, em diferentes sistemas agrícolas, onde é possivel utilizar a canola como cultura sucessora.

\section{LITERATURA CITADA}

BROWN, P. D. et al. Allelochemicals produced during glucosinolate degradation in soil. J. Chem. Ecol., v. 17, n. 4, p. 2021-2034, 1991

BUHLER, D. D. Challenges and opportunities for integrated weed management. Weed Sci., v. 50, n. 2, p. 273-280, 2002.

CARVAlHO, G. J.; FONTANÉTTI, A. A.; CANÇADO, C. T. Potencial alelopático do feijão de porco (Canavalia ensiformes) e da mucuna preta (Stilozobium aterrimum) no controle da tiririca (Cyperus rotundus). Ci. Agrotec., v. 26, n. 3, p. 647-651, 2002.

CASTRO, P. R. C. et al. Efeitos alelopáticos de alguns extratos vegetais na germinação do tomateiro (Lycopersicon esculentum Mill. Cv. Santa Cruz). Planta Daninha, v. 6, n. 2, p 79-85, 1983

EBERLEIN, C. V. et al. Glucosinolate production by five field-crown Brassica napus cultivars used as green manures. Weed Technol., v. 12, n. 4, p. 712-718, 1998.

ELAKOVICTH, S. D. Bioassays applied to allelopathic herbaceous vascular hydrophytes. In: INDERJIT, K. M. N.; FOY, C.L. (Eds.) Principles and practices in plant ecology. Boca Raton: CRCPress, 1999. p. 45-56.

JACOBI, U. S.; FLECK, N. G. Avaliação do potencial alelopático de genótipos de aveia no início do ciclo. Pesq. Agropec. Bras., v. 35, n. 1, p. 11-19, 2000.

JÖNSSON, M. Responses to oilseed rape and cotton volatiles in insect herbivores and parasitoids. 2005. 205 f. Tese (Doctor Thesis in Crop Science) - Swedish University of Agricultural Sciences, Alnarp, 2005.

KATO-NAGUCHI, H. et al. Allelopathy of oats. I. Assessment of allelopathic potential of extract of oat shoots an identification of an allelochemical. J. Chem. Ecol., v. 20, n. 2, p. 309-314, 1994.

KRISHNAN, G.; HOLSHOUSER, D. L.; NISSEN, S.J. Weed control in soybean (Glycine max) with green manure crops. Weed Technol., v. 12, n. 1, p. 97-102, 1998.

Planta Daninha, Viçosa-MG, v. 26, n. 4, p. 717-724, 2008 
MAIRESSE, L. A. S. Avaliação da bioatividade de extratos de espécies vegetais, enquanto excipientes de aleloquímicos. 2005. 329 f. Tese (Doutorado em Agronomia) - Universidade Federal de Santa Maria, Santa Maria, 2005

NORSWORTHY, J. K. Allelopathic potential of wild radish (Raphanus raphanistrum). Weed Technol., v. 17, n. 2, p. 307-313, 2003.

NORSWORTHY, J. K.; MEEHAN. J. T. Use of isothiocyanates for suppression of Palmer amaranth (Amaranthus palmeri), pitted morningglory (Ipomoea lacunosa), and yellow nutsedge (Cyperus esculentus). Weed Sci., v. 53, n. 6, p. 884-890, 2005.

OERLEMANS, K. et al. Thermal degradation of glucosinolates in red cabbage. Food Chem., v. 95, n. 1, p. 19-29, 2006.
PETERSEN, J. et al. Weed supression by release of isothiocyanates from turnip-rape mulch. Agron. J., v. 93, n. 1, p. 37-43, 2001.

RICE, E. L. Allelopathy. New York: Academic Press, 1984. $422 \mathrm{p}$

RIZZARDI, M. A. et al. Potencial alelopático da cultura da canola (Brassica napus L. var. oleifera) na supressão de picão-preto (Bidens sp.) e soja. R. Bras. Agroci., 2008 (Trabalho aceito para publicação)

SOUZA FILHO, A. P. S. et al. Efeitos do potencial alelopático de três leguminosas forrageiras sobre três invasoras de pastagens. Pesq. Agropec. Bras., v. 32, n. 2, p. $165-170,1997$

WU, H. et al. Crop cultivars with allelopathic capability. Weed Res., v. 39, n. 3, p. 171-180, 1999. 